\title{
Temporal Restrictions on Emissions Trading and the Implications for the Carbon \\ Futures Market: Lessons from the EU Emissions Trading Scheme
}

\author{
George Daskalakis \\ Norwich Business School, University of East Anglia, Norwich NR4 7TJ, UK \\ Tel.: +44 (0)1603 592309, Fax: +44 (0)1603 593343, E-mail: g.daskalakis@uea.ac.uk
}

\begin{abstract}
Prohibiting the intertemporal trading of emission allowances induces positive risk premia in futures prices when the trading of the contracts and their expiry take place in time periods separated by this trading ban. In Phase I of the EU Emissions Trading Scheme (EU ETS) these were in the order of about $28 \%$ of the futures price on average, depending on the contract's expiry in Phase II. Environmental policy makers should avoid such restrictions as they result in increased hedging costs for polluters that are, since emission allowances represent opportunity costs, potentially borne by consumers.
\end{abstract}

Keywords: Emission allowances; Intertemporal trading; Carbon futures; Risk premia; EU ETS JEL Classification: G13; Q02; Q58

\section{Introduction}

The cost effectiveness of environmental policies based on cap-and-trade systems for emission allowances (or permits) is intimately related to the flexibility given to polluters with respect to the timing, extent and manner of emissions abatement (see Montgomery, 1972 and the review by Cropper and Oates, 1992). This flexibility is thought to be enhanced if the intertemporal trading of the permits is allowed (e.g., Rubin, 1996; Kling and Rubin, 1997). Contrary to the consensus view in the environmental economics literature however, the EU member states decided in 2003 to restrict flexibility by prohibiting the trading of the carbon dioxide $\left(\mathrm{CO}_{2}\right)$ emission allowances from Phase I (2005-2007) to Phase II (2008-2012) of the EU ETS (Directive 2003/87/EC). This was based on concerns that unless this policy was adopted, the achievement of the Kyoto obligations for the EU could 
be jeopardized (see, for example, Parsons et al., 2009 for a discussion of this issue). Specifically, the rationale was that by not allowing the 'banking' of Phase I emission allowances to Phase II, a stricter cap would be essentially in place for Phase II. However, a simpler approach would have been to impose directly stricter caps in Phase II in order to account for any Phase I emission allowances banked. As expected, the decision attracted considerable criticism, with both academics and practitioners pointing out its negative implications from an environmental (Schleich et al., 2006), economic (Godal and Klaasen, 2006) and financial perspective (Daskalakis and Markellos, 2008). In response, the EU Commission started reviewing in 2006 the functioning of the EU ETS and adopted a year later several improvements regarding its operation from 2008 onwards. The main and most anticipated one was the removal of the inter-phase trading ban of the carbon permits (Directive 2009/29/EC). For a thorough description of the EU ETS, along with a discussion regarding the scheme's operation during its first two phases see Daskalakis et al. (2011).

The implications of the intertemporal trading ban in the EU ETS from a financial perspective have been extensively discussed in the extant literature (see Daskalakis et al., 2011, inter-alia). The focus, however, has been on the spot market, whereas little has been said on the consequences of this policy for the futures market. This is the issue I address in this note, with my objective being to provide environmental policy insights from the standpoint of the participants in the carbon futures market. Such insights are both topical and important as there are currently about 100 emissions trading schemes being planned (or considered) around the world after the 'Paris Agreement' for a worldwide effort to keep the global average temperature increase below 2 degrees Celsius came into force in November 2016 (World Bank et al., 2016). Naturally, further than the establishment of a spot market, each of these schemes is expected to eventually develop a corresponding futures market so that, on the one hand, polluters are able to manage their carbon risk exposure and, on the other hand, speculators to enter the market, bring the necessary liquidity and in turn, improve market efficiency. The latter highlights the fact that the role of the carbon futures market is not limited to simply providing a hedging platform for polluters, but in fact is central in the success of an emissions trading scheme. The reason is that the achievement of the required emissions reductions in a cost-effective manner depends on whether the market itself is efficient and, therefore, the prices of the traded permits reflect their fundamentals (i.e., marginal 
abatement costs), as only then polluters will be able to reach optimal abatement decisions (see Daskalakis, 2013 for a discussion). Consequently, when deciding the different aspects of an emissions trading scheme, policy makers need to have a clear understanding of the implications of their decisions for the futures market. Whether to allow the trading of the permits between different periods of the scheme is one of the first decisions to be made. Hence, the policy insights regarding this issue that can be drawn from the experience gained from the operation of the largest and oldest mandatory emissions trading scheme in the world, the EU ETS, are indeed invaluable.

\section{Relationship between spot and carbon futures prices: Background}

A main function of the EU ETS futures market is to provide a platform for polluters to hedge carbon price risk. To facilitate this, carbon futures (i.e., futures contracts with underlying carbon emission allowances) with expiry within not only the current but also the next phase of the scheme are traded. For example, in 2005 (beginning of Phase I) contracts with expiry up to December 2012 (end of Phase II) were available. Similarly, in 2008 (beginning of Phase II) futures with expiry up to December 2020 (end of Phase III) were traded. Thus, carbon futures can be classified either as 'intra-phase' or 'interphase' contracts. The former, are those that initiate and expire within the same phase of the scheme while, the latter, are those that initiate in one phase and expire within the next one. This categorization allows highlighting the key implication of the intertemporal trading ban for the carbon futures market. When the permits cannot be transferred from the current phase to the next, the spot emission allowances underlying the inter-phase futures are a different asset than the underlying spot permits of the intraphase contracts. More importantly, as the underlying of the inter-phase futures is not a traded asset in the current period, the spot-futures price relationship (or equivalently the pricing mechanism) between these two categories of contracts differs.

To illustrate this, Figure 1 presents the daily price evolution of the spot permits and of the most liquid inter- and intra-phase carbon futures traded in Phase I of the EU ETS. Spot prices are from the French PowerNext, the primary spot carbon exchange in that period. Futures prices are for contracts with December expiry in the years 2006 to 2010 (Dec-06 to Dec-10 contracts) traded in the Londonbased Intercontinental Exchange (ICE), the main carbon futures exchange in the EU ETS. For the 
specification of the carbon futures and a description of the spot and futures exchanges in the two first phases of the EU ETS see Daskalakis et al. (2011). Based on the classification of the carbon futures introduced above, Dec-06 and Dec-07 were intra-phase contracts and the remaining three (Dec-08, Dec09 and Dec-10) inter-phase futures. The key observation from this figure is that although intra-phase futures prices followed very closely the price evolution of the spot permits, this was not the case for the inter-phase contracts.

\section{[Insert Figure 1 about here]}

Further insights are gained from Figure 2 that plots the prices of the three inter-phase futures in the period 2008 to 2010, that is, from the beginning of Phase II up to the expiry of the longest expiring contract (Dec-10). Spot prices from BlueNext (PowerNext was acquired by BlueNext in 2007) are also presented for comparison purposes. As seen in this figure, when the trading of the inter-phase futures was taking place in the same period as their expiry, their prices followed closely the prices of the spot permits, similarly to the case of the intra-phase futures in Phase I.

\section{[Insert Figure 2 about here]}

For explaining this behavior, Daskalakis et al. (2009) argued that since storing the permits is costless, and there is no advantage of holding a long futures position in comparison to holding a long spot one, intra-phase futures prices should be related to spot prices through the cost-of-carry model of Kaldor (1939), Working (1948) and Telser (1958), with zero storage costs and no convenience yield. They further pointed out that this should also be the case for the inter-phase futures when their trading takes place in the same period as their expiry. Indeed, the empirical evidence they provided suggest that any mispricing of the cost-of-carry model in these two cases is in the order of the transaction costs. For the inter-phase futures when traded in a different period than their expiry however, they explained that since the underlying of these contracts is not at that point traded, the cost-of-carry model is no longer applicable. Instead, they proposed a futures pricing model based on an empirically consistent continuous-time process for the spot prices. 


\section{Risk premia in inter-phase carbon futures prices}

I revisit here the relationship between inter-phase futures and spot carbon prices when the trading of the contracts and their expiry take place in different time periods due to an intertemporal trading ban. In contrast to Daskalakis et al. (2009), I follow an approach that can be traced back to the classical hedging-pressure literature (e.g., Keynes, 1930; Hicks, 1939; Cootner, 1960; Hazuka, 1984), according to which, futures prices for non-storable assets consist of two parts: the expected spot price of the underlying at the contract's expiry and a positive risk premium (see Daskalakis et al., 2015 for an application of this type of analysis on electricity futures prices). Assuming two types of investors, hedgers (risk averse investors) and speculators (less risk averse investors), this premium represents the compensation the latter require from the former for taking short positions and assuming spot price risk. Thus, the pricing relationship of a futures contract in this approach is given by:

$$
F_{t, T}=E_{t}\left(S_{T}\right)+R P_{t}
$$

where, $F_{t, T}$ is the price at time $t$ of a futures contract expiring at time $T, E_{t}\left(S_{T}\right)$ is the expectation at time $t$ for the spot price of the underlying at expiry, and $R P_{t}$ is the risk premium at time $t$. Substituting the expectation by the observed spot price at the contract's expiry we obtain the relationship of the socalled ex-post (or realized) risk premium:

$$
R P_{t}=F_{t, T}-S_{T}
$$

In the context of the EU ETS, polluters wishing to eliminate carbon price risk (hedgers) take long futures positions for securing at a pre-specified price the number of permits they estimate they will need in the future for attaining environmental compliance. The counterparties (speculators) are polluters who believe they will manage to abate emissions and, therefore, will have surplus permits which they sell in the futures market. When a trading ban of emission allowances from the current to the next phase of the scheme is in place, speculators face an increased risk of failing environmental compliance in the next phase and thus, having to pay the penalties set. This is because, on the one hand, the current traded spot permits cannot be transferred to the next phase and, on the other hand, information regarding the permit allocations for the next phase only become known at the end of the current one. Based on these 
considerations, one would expect to find during Phase I of the EU ETS positive risk premia in the interphase futures prices.

To this end, I calculate through equation (2) the ex-post risk premia for the inter-phase futures Dec-08, Dec-09 and Dec-10 in Phase I. The daily evolution of these is depicted in Figure 3. Descriptive statistics are presented in Table 1. The results indicate that there were indeed significant positive, on average, risk premia in the prices of the three inter-phase futures in Phase I. Specifically, the mean premium was about $€ 5, € 6.5$ and $€ 7.3$ per permit for the Dec-08, Dec-09 and Dec-10 contract respectively, with the increase along with time to expiry reflecting the time value of money effect. Expressing these as a ratio to the corresponding futures price, it seems that the risk premia accounted for a considerable proportion of the inter-phase futures prices. Specifically, they accounted for approximately $22 \%$ of the permit price on average in the case of the Dec-08 contract, $29 \%$ in the case of the Dec-09 futures and 33\% for the Dec-10. Finally, although negative risk premia are found for all inter-phase futures, their number is rather limited: out of 624 daily risk premia computed for each contract, only 44 are negative for the Dec-08, 11 for the Dec-09 and 2 for the Dec-10. More importantly, these are clustered in a period during which: a) Phase I spot permits were trading for a few cents due to the combined effect of the generous emission caps provided in that phase and the inter-phase trading ban (see Parsons et al., 2009 for a discussion of this issue), b) Phase II permit allocations had not yet been determined, and c) the revisions of the EU ETS were still undergoing. A plausible explanation for these negative premia, therefore, can be based on market participants' concerns that should the emission cap in Phase II was not set at an appropriate level, and the inter-phase trading ban removed, demand for Phase II spot permits would be virtually non-existent, similarly to the spot permits in the final year of Phase I.

[Insert Figure 3 and Table 1about here]

\section{Concluding remarks}

An intertemporal trading ban of emission allowances results in increased hedging costs for polluters. These come in the form of positive risk premia in futures prices when the trading of the contracts and their expiry take place in different time periods due to the ban. Since emission allowances represent 
opportunity costs for polluters, it can be expected these costs to, at least partly, pass-through to consumers. In fact, according to Sijm et al. (2006), the carbon cost pass-through rate in Europe varies between $60 \%$ and $100 \%$. Therefore, the cost implication of an intertemporal trading ban of emission allowances for consumers can indeed be substantial. Hence, environmental policy makers should be aware that imposing temporal restrictions in emissions trading has significant cost implications for participants in the futures market and potentially for consumers. Consequently, imposing an intertemporal trading ban of emission allowances as a mechanism for setting stricter emission caps in future periods of an emissions trading scheme is a practice that should be avoided.

\section{References}

Cootner, P.H. (1960). "Returns to speculators: Telser vs. Keynes.” Journal of Political Economy 68: 396-404.

Cropper, M.L., Oates, W.E. (1992). "Environmental economics: A survey.” Journal of Economic Literature 30: 675-740.

Daskalakis, G. (2013). "On the efficiency of the European carbon market: New evidence from Phase II.” Energy Policy 54: 369-375.

Daskalakis, G., Ibikunle G., Diaz-Rainey, I. (2011). “The $\mathrm{CO}_{2}$ trading market in Europe: A financial perspective.” In: Dorsman, A., et al. (eds.), Financial Aspects in Energy. Heidelberg: Springer, pp. $51-67$.

Daskalakis, G., Markellos, R.N. (2008). “Are the European carbon markets efficient?” Review of Futures Markets 17: 103-128.

Daskalakis, G., Psychoyios, D., Markellos, R.N. (2009). "Modeling $\mathrm{CO}_{2}$ emission allowance prices and derivatives: Evidence from the European trading scheme.” Journal of Banking \& Finance 33: 12301241.

Daskalakis, G., Symeonidis, L., Markellos, R.N. (2015). "Electricity futures prices in an emissions constrained economy: Evidence from European power markets.” The Energy Journal 36: 1-33.

Godal, O., Klaasen, G. (2006). "Carbon trading across sources and periods constrained by the Marrakesh accords.” Journal of Environmental Economics \& Management 51: 308-322. 
Hazuka, T.B. (1984). "Consumption betas and backwardation in commodity markets." Journal of Finance 39: 647-655.

Hicks, Richard John (1939). Value and Capital: An Inquiry into some Fundamental Principles of Economic Theory. Oxford: Oxford University Press.

Kaldor, N. (1939). "Speculation and economic stability.” Review of Economic Studies 7: 1-27.

Keynes, Maynard John (1930). A Treatise on Money. London: Macmillan Publishers.

Kling, C., Rubin, J.D. (1997). "Bankable permits for the control of environmental pollution.” Journal of Public Economics 64: 101-115.

Montgomery, W. (1972). "Markets in licenses and efficient pollution control programs." Journal of Economic Theory 5: 395-418.

Parsons, J.E., Ellerman, A.D., Feilhauer, S. (2009). "Designing a U.S. market for $\mathrm{CO}_{2}$." Journal of Applied Corporate Finance 21: 79-86.

Rubin, J.D. (1996). “A model of intertemporal emissions trading, banking, and borrowing.” Journal of Environmental Economics \& Management 31: 269-286.

Schleich, J., Ehrhart, K.M., Hoppe, C., Seifert, S. (2006). "Banning banking in EU emissions trading?” Energy Policy 34: 112-120.

Sijm, J., Neuhoff, K., Chen, Y. (2006). "CO 2 cost pass-through and windfall profits in the power sector." Climate Policy 6: 49-72.

Telser, L.G. (1958). "Future trading and the storage of cotton and wheat." Journal of Political Economy 66: $233-255$.

Working, H. (1948). "Theory of the inverse carrying charge in futures markets." Journal of Farm Economics 30: 1-28.

World Bank, Ecofys, Vivid Economics, 2016. State and Trends of Carbon Pricing 2016 (October), World Bank, Washington DC. 
Figure 1. Emission allowance spot and futures prices in Phase I

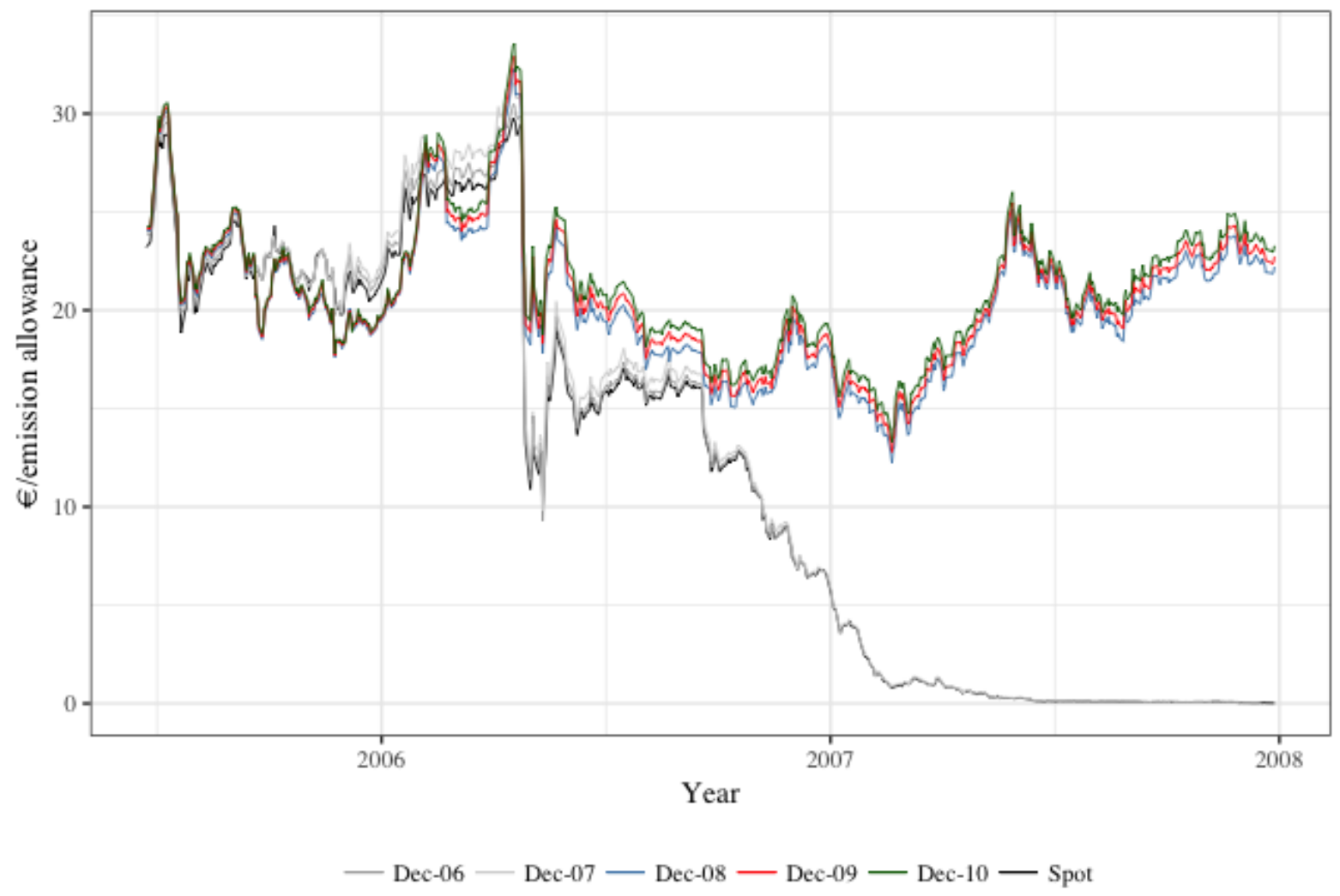

Figure 2. Emission allowance spot and futures prices in Phase II

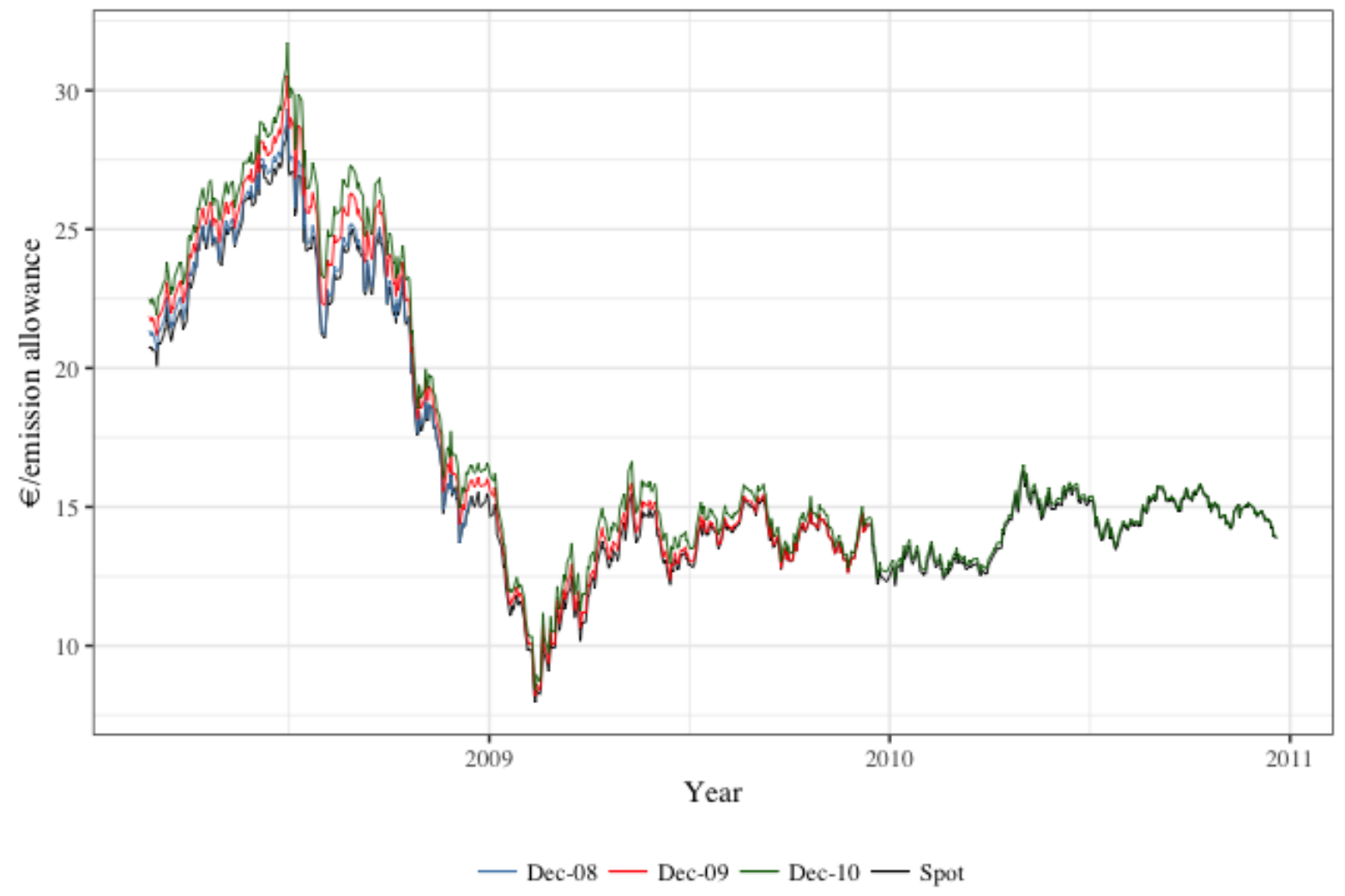


Figure 3. Ex-post risk premia in inter-phase carbon futures prices

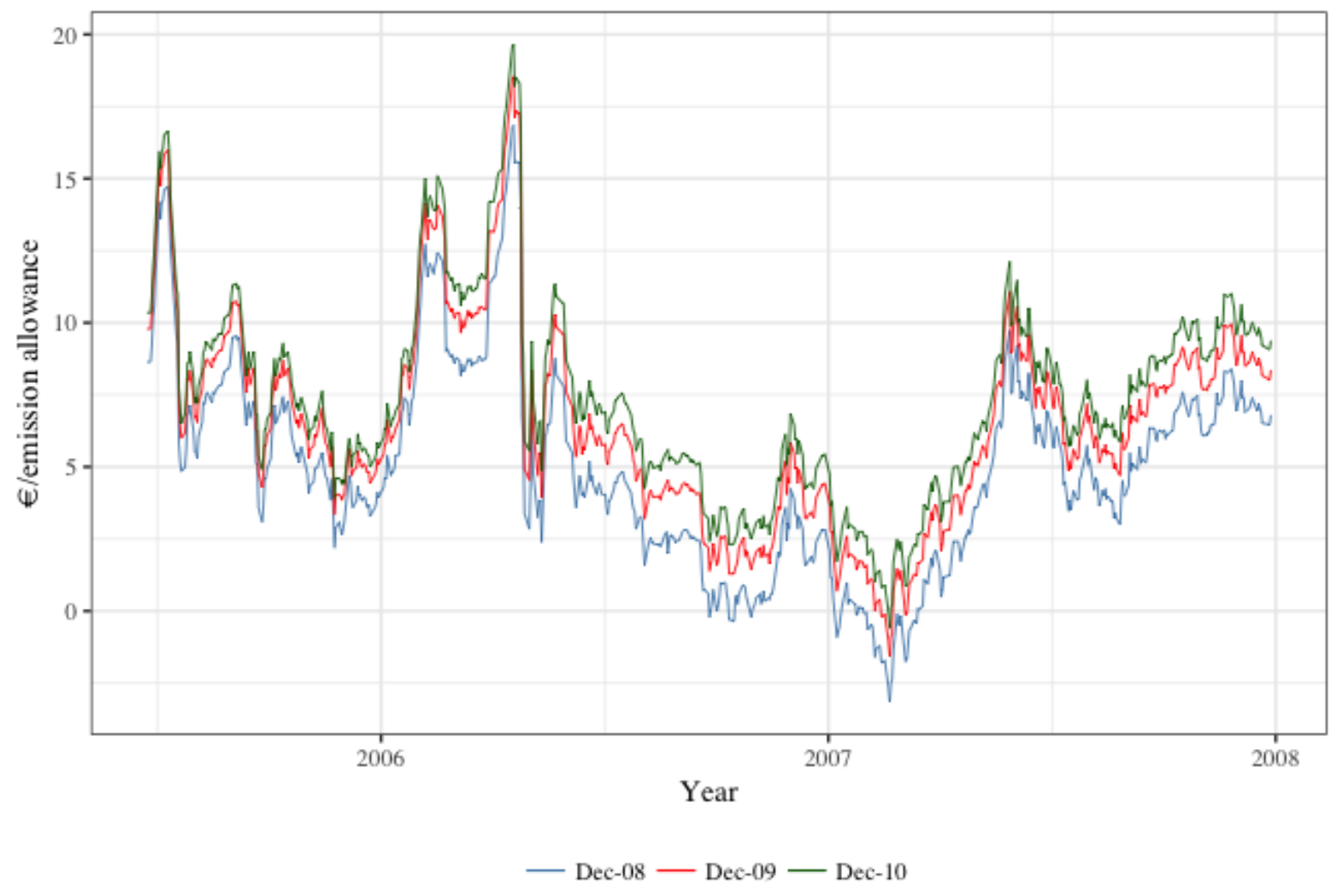

Table 1. Descriptive statistics of ex-post risk premia in inter-phase carbon futures prices

\begin{tabular}{cccccc}
\hline Contract & Mean & Median & Minimum & Maximum & St. Dev. \\
\hline Dec-08 & 4.96 & 4.69 & -3.16 & 16.84 & 3.50 \\
Dec-09 & 6.45 & 6.19 & -1.56 & 18.54 & 3.46 \\
Dec-10 & 7.34 & 7.06 & -0.60 & 19.65 & 3.43 \\
\hline
\end{tabular}

Note: Risk premia are expressed in $€ /$ emission allowance. 